\title{
Atividade sérica das enzimas musculares em muares submetidos à prova de resistência de $100 \mathbf{k m}^{1}$
}

\author{
Evandro Pereira Neto ${ }^{2}$, Anderson L. Araújo ${ }^{2}$, Ligia A. Cunha ${ }^{3}$, Márcio P. Barcellos ${ }^{4}$, \\ Odael Spadeto $\mathrm{Jr}^{5}$ e Clarisse S. Coelho ${ }^{6 *}$
}

\begin{abstract}
Pereira Neto E., Araújo A.L., Cunha L.A., Barcellos M.P., Spadeto Jr O. \& Coelho C.S. 2013. [Serum activity of muscular enzymes in mules after a 100 km endurance exercise.] Atividade sérica das enzimas musculares em muares submetidos à prova de resistência de $100 \mathrm{~km}$. Pesquisa Veterinária Brasileira 33(11):1385-1389. Programa de Mestrado em Ciência Animal, Universidade Vila Velha, Rua Comissário José Dantas de Melo 21, Vila Velha, ES 29102-770, Brazil. E-mail: clarisse.coelho@uvv.br

The aim of this study was to evaluate the influence of an exercise of submaximal intensity on serum concentrations of aspartate aminotransferase (AST), creatine kinase (CK) and lactate dehydrogenase (LDH) in mules during endurance exercise in Espirito Santo, Brazil. Serum samples were obtained from 20 mules in four different moments: at rest (T0); after 54 km (T1); after $80 \mathrm{~km}$ (T2); and after $100 \mathrm{~km}$ (T3). Samples were analyzed at Laboratório Clínico Veterinário (CEMEVES). Serum AST analysis revealed mean values of 341.7 $\pm 73.9 \mathrm{UI} / \mathrm{L}, 403.1 \pm 78.4 \mathrm{UI} / \mathrm{L}, 410.5 \pm 70.5 \mathrm{UI} / \mathrm{L}$ and $426.5 \pm 66.7 \mathrm{UI} / \mathrm{L}$, respectively at moments T0, T1, T2 and T3. LDH mean values recorded in T0, T1, T2 and T3 were, respectively, $423.1 \pm 101.8 \mathrm{UI} / \mathrm{L}, 534.4 \pm 131.8 \mathrm{UI} / \mathrm{L}, 628.5 \pm 100.6 \mathrm{UI} / \mathrm{L}$ and $823.4 \pm 273.2 \mathrm{UI} / \mathrm{L}$. Finally, when evaluating CK, median values recorded were $231.3 \mathrm{UI} / \mathrm{L}, 310.6 \mathrm{UI} / \mathrm{L}, 253.2$ UI/L and 476.0 UI/L, respectively on the moments T0, T1, T2 and T3. Results showed that the physical exercise imposed leaded to significantly increase in serum AST and LDH and did not change serum CK.
\end{abstract}

INDEX TERMS: Muscular enzymes, AST, CK, LDH, exercise, mules.

RESUMO.- 0 presente estudo teve por objetivo avaliar a influência do exercício físico de intensidade submáxima sobre as concentrações séricas de aspartato aminotransferase (AST), creatinoquinase (CK) e lactato-desidrogenase (LDH) em muares durante prova de enduro de $100 \mathrm{~km}$ realizada no estado do Espírito Santo. Para tal foram obtidas amostras de soro de 20 muares em três momentos assim definidos: no repouso (T0); após $54 \mathrm{~km}$ de percurso

\footnotetext{
${ }^{1}$ Recebido em 17 de agosto de 2013.

Aceito para publicação em 5 de dezembro de 2013

${ }^{2}$ Programa de Mestrado em Ciência Animal, Universidade Vila Velha (UVV), Rua Comissário José Dantas de Melo 21, Vila Velha, ES 29102-770, Brasil.

${ }^{3}$ Medica Veterinária Autônoma, Av. Delios Silva Brito 630/302, Vila Velha, ES 2912-904.

${ }^{4}$ Centro de Diagnóstico Veterinário, CEMEVES. Av. Pedro Fonseca 155, Vitória, ES 29041-060.

${ }^{5}$ Curso de Medicina Veterinária, UVV, Vila Velha, ES..

${ }^{6}$ Programa de Mestrado em Ciência Animal, UVV, Vila Velha, ES 29102770. *Autor para correspondência: clarisse.coelho@uvv.br
}

(T1); após 80 km de percurso (T2); e após 100 km de percurso (T3). As referidas amostras foram encaminhadas ao Laboratório Clínico Veterinário (CEMEVES) para processamento. Na avaliação da atividade sérica de AST, os valores médios registrados nos momentos $\mathrm{T} 0, \mathrm{~T} 1, \mathrm{~T} 2$ e T3 foram, respectivamente, de 341,7 $\pm 73,9 \mathrm{UI} / \mathrm{L}, 403,1 \pm 78,4 \mathrm{UI} / \mathrm{L}$, $410,5 \pm 70,5$ UI/L e 426,5 $\pm 66,7$ UI/L. Na avaliação da atividade sérica da LDH, os valores médios registrados foram de $423,1 \pm 101,8 \mathrm{UI} / \mathrm{L}, 534,4 \pm 131,8 \mathrm{UI} / \mathrm{L}, 628,5 \pm 100,6 \mathrm{UI} / \mathrm{L} \mathrm{e}$ $823,4 \pm 273,2 \mathrm{UI} / \mathrm{L}$, respectivamente, nos momentos T0, T1, T2 e T3. Por fim, na avaliação da atividade sérica da CK os valores de mediana foram de 231,3 UI/L, 310,6 UI/L, 253,2 $\mathrm{UI} / \mathrm{L}$ e 476,0 UI/L, respectivamente nos momentos T0, T1, T2 e T3. A análise dos resultados demonstrou que o exercício físico imposto levou ao aumento significativo das atividades séricas de AST e LDH e não alterou as concentrações séricas de CK.

TERMOS DE INDEXAC̄̃̃O: Enzimas musculares, AST, CK, LDH, exercício, muares. 


\section{INTRODUÇÃO}

Os muares são animais de grande popularidade no meio rural e urbano devido a sua rusticidade e vigor físico. São animais capazes de executar trabalho em diferentes tipos de terrenos, com declive e aclive, e também se adéquam aos diferentes tipos de clima presente no Brasil (De Oliveira 2004). Além de serem utilizados na lida diária, também são utilizados durante o lazer (Ribeiro et al. 2009).

Da mesma forma que os cavalos e os asininos, os muares são utilizados como atletas em diversas provas, destacando-se aquelas onde se avalia o andamento e as provas de resistência, as cavalgadas. Nestas últimas, os animais são submetidos à exercício de intensidade submáxima e longa duração (Ribeiro et al. 2004).

Nos últimos anos, várias pesquisas vêm sendo feitas com o intuito de determinar a resposta orgânica frente ao exercício físico imposto e seus resultados ajudam a avaliar a performance atlética, bem como a diagnosticar lesões na musculatura esquelética nos animais tidos como mal condicionados (Santos 2006). Em sua grande maioria, tais pesquisas são realizadas com equinos (Martins et al. 2005, Fransciscato et al. 2006, Gomide et al. 2006, Kowal et al. 2006, Pritchard et al. 2009). Ainda há muita inconsistência na literatura na tentativa de se estipular um valor de referência para tais avaliações, por conta das diferenças em intensidade e duração do exercício ao qual o animal está sendo submetido. Um dos fatores que dificulta ainda mais a avaliação de muares é a falta de valores de referência, sendo sempre comparados aos valores determinados para equinos (Dugat et al. 2010).

A aspartato aminotransferase (AST) é a enzima que catalisa a transaminação de L-aspartato e alfa-cetoglutarato em oxalacetato e glutamato, estando presente em quase todos os tecidos, principalmente fígado e musculaturas esqueléticas e cardíaca. A enzima lactato desidrogenase (LDH) catalisa a reação reversível de L-lactato para piruvato, encontrando-se presente em grande quantidade na musculatura esquelética. A análise da atividade sérica de ambas não é específica para função muscular. A creatinoquinase (CK) é uma enzima de alta especificidade para lesões musculares, encontrada principalmente no citosol das células musculares (músculos esquelético e cardíaco) (Valberg 2008).

Robinson (2003) cita valores para AST de 141-330 UI/L e para CK de 2-147 UI/L em equinos da raça Puro Sangue Inglês (PSI). Também em equinos da raça PSI, no repouso, VALBERG (2008) descreveu valores médios de 296,0 $\pm 70,0$ UI/L para a atividade de AST, de 12,9 $\pm 5,2 \mathrm{UI} / \mathrm{L}$ para a atividade enzimática de CK e de 252,0 $\pm 63,0 \mathrm{UI} / \mathrm{L}$ para a atividade sérica de LDH. Balarin et al. (2005), que também utilizaram PSI, obtiveram valores de 374,05 $\pm 67,07 \mathrm{UI} / \mathrm{L}$ para machos e $360,85 \pm 73,70$ UI/L para fêmeas. Franciscato et al. (2006) citaram valores médios de 209,67 UI/L para AST e de 159,81 UI/L para CK em equinos da raça Crioula em treinamento. Trabalho mais recente de Pritchard et al. (2009) citou valores de AST sérico de 189456 UI/L e valores de 123-358 UI/L para CK sérico em equinos.
Geralmente, a determinação sérica das atividades da AST, CK e LDH é usada na avaliação dos efeitos do exercício físico sobre a musculatura (Câmara-Silva et al. 2007, Valberg 2008). Segundo Valberg (1996), a permeabilidade do sarcolema aumenta durante o exercício e as enzimas podem escoar para o plasma, porém os resultados descritos na literatura são controversos, com alguns autores citando influência positiva (ou seja aumento dos valores sanguíneos das referidas variáveis) ou a não interferência do exercício sobre estes constituintes sanguíneos (Rose et al. 1980, Freestone et al. 1991, Balarin et al. 2005, Kowal et al. 2006, Padalino et al. 2007). Hodgson \& Rose (1994) e Câmara-Silva et al. (2007) ressaltam que as concentrações dessas enzimas poderiam ainda ser influenciadas pela fase de treinamento e pelo tipo de exercício e Harris et al. (1998) citam que, se a duração do exercício for mantido constante, a intensidade do mesmo, ou seja, a velocidade imposta, determinaria o aumento de suas concentrações séricas.

0 objetivo do presente trabalho foi avaliar a influência do exercício físico sobre as enzimas musculares (AST, LDH e CK séricos) em muares ao longo de uma cavalgada de 100 km, realizada no estado do Espírito Santo.

\section{MATERIAL E MÉTODOS}

O presente projeto foi aprovado pelo Conselho de Ética (CEUA, UVV), sendo registrado sob o número 134/2010. Foram utilizados 20 muares, pesando em média $410 \pm 40 \mathrm{~kg}$, com idade variando entre três e dez anos (média de 5,5 $\pm 2,8$ anos de idade), considerados clinicamente hígidos, mediante exame clínico (exame físico e hemograma). Estes animais pertencem a criatórios localizados em diferentes municípios do estado do Espírito Santo, Brasil. A temperatura média local de $23^{\circ} \mathrm{C}$ e umidade relativa do ar de $78 \%$, típicas de clima tropical de altitude (ameno).

Todos os animais foram submetidos ao mesmo tipo de manejo alimentar e sanitário. A alimentação dos animais foi baseada nos relatos de Ralston (1988), sendo fornecido feno de coast-cross (Cynodon dactylon x Cynodon nlemfluensis) ad libitum e ração comercial (DoEqui TopQuality), com 12\% de proteína bruta, a 1\% do peso corporal, divididos em três vezes ao dia. A água e sal mineral foram fornecidos ad libitum.

Na presente pesquisa, os animais executaram $100 \mathrm{~km}$ de cavalgada no evento esportivo denominado Tropeada do Imigrante. No primeiro dia, os animais foram montados às $5 \mathrm{~h}: 00$, saindo de Anchieta (latitude $20^{\circ} 48^{\prime} 21^{\prime \prime}$ Sul e longitude $40^{\circ} 38^{\prime} 52^{\prime \prime}$ Oeste), e percorreram cerca de $24 \mathrm{~km}$, chegando em Cachoeira Alta, distrito de Alfredo Chaves, aproximadamente às 13h:00, momento em que água e alimento foram oferecidos. Próximo às 15h:00, os animais retomaram o percurso, chegando ao Quarto Território, também distrito de Alfredo Chaves (latitude 20³8'06" Sul e longitude $40^{\circ} 45^{\prime} 00^{\prime \prime}$ Oeste) às $19 \mathrm{~h}: 30$, totalizando $54 \mathrm{~km}$ no primeiro dia, quando novamente água e alimento foram oferecidos. No dia seguinte, os animais iniciaram o trajeto no mesmo horário do dia anterior, parando para descanso quando atingiram a marca dos $80 \mathrm{~km}$ por volta de 15h:00 em Pombal de Cima, distrito de Vargem Alta (latitude 2040'15" sul e longitude 41ํำ' $25^{\prime \prime}$ oeste). Finalizaram os $100 \mathrm{~km}$ de percurso às 20h:00 do segundo dia em Cachoeira do Furlan, no município de Castelo (latitude $20^{\circ} 36^{\prime} 13^{\prime \prime}$ Sul e longitude $41^{\circ} 11^{\prime} 05^{\prime \prime}$ Oeste).

Cada animal foi avaliado em quatro momentos: antes - T0 (obtida antes da cavalgada, com o animal em repouso), T1 (obtida após $54 \mathrm{~km}$ do percurso), T2 (obtida após $80 \mathrm{~km}$ do percurso) e T3 (obtida após $100 \mathrm{~km}$ do percurso). Nesses momentos de ava- 
liação, amostras de sangue foram obtidas, após antissepsia local, por meio de venopunção da jugular com agulhas descartáveis (25mm x 0,8mm), utilizando-se sistema a pressão negativa, em tubos de vidro siliconizados sem anticoagulante com capacidade de $9 \mathrm{~mL}$, para as determinações séricas de AST, LDH e CK. Todas as 80 amostras foram transportadas sob refrigeração ao Centro de Diagnóstico Veterinário, onde foram imediatamente centrifugadas (3500rpm) durante 10 minutos (Centrífuga modelo TDL80-2B, Marca Centribio) para separação de soro. Além dessas análises, nesses mesmos momentos, foi feita a avaliação da frequência cardíaca e determinação do lactato plasmático, visando estabelecer a intensidade do exercício físico imposto.

No soro, a atividade da enzima AST foi determinada através de kit comercial (Katal 15B) (Bergmeyer 1985). A atividade sérica de CK foi quantificada utilizando-se kit comercial (Katal 47B) (Schmid \& Forstner 1986). Por fim, a atividade sérica da LDH foi determinada usando kit comercial (Katal 08B) (Bergmeyer 1985). Todo o processamento foi feito em analisador bioquímico semi-automático (Bioplus - BIO 200), em comprimento de onda de $340 \mathrm{~nm}$

A análise dos resultados foi realizada utilizando-se o programa estatístico computadorizado GraphPad InStat (versão 3.0). Devido à distribuição gaussiana dos dados registrados para as atividades séricas de AST e LDH , os dados foram avaliados através de testes paramétricos (análise de variância - ANOVA) seguido da comparação entre médias (teste de Tukey) com nível de significância de $5 \%$. Já a análise dos resultados referentes ao CK sérico foi feita usando testes não paramétricos devido a distribuição não gaussiana dos dados. 0 teste usado em sua avaliação foi Kruskal-Wallis com nível de significância de 5\%. Nestas análises levou-se em consideração a influência do exercício físico sobre as concentrações das variáveis estudadas (análise de variância one-way).

\section{RESULTADOS}

No Quadro 1 estão apresentados os valores médios e desvios-padrão para os valores séricos de AST e LDH, além dos valores de p obtidos na análise de variância (ANOVA). No Quadro 2 estão apresentados os valores da mediana, valores máximos e mínimos encontrados para a atividade sérica CK.

Na avaliação dos resultados obtidos, foi possível observar que o exercício físico imposto influenciou de forma significativa a atividade sérica de AST $(p=0,0049)$ e de LDH $(\mathrm{p}<0,0001)$.

Não houve influência do tipo de exercício imposto sobre a atividade sérica de CK $(\mathrm{p}=0,1462)$ ao longo do período experimental.

\begin{tabular}{|c|c|c|c|c|c|}
\hline & T0 $(n=20)$ & $\mathrm{T} 1(\mathrm{n}=12)$ & $\mathrm{T} 2(\mathrm{n}=17)$ & T3 (n=14) & $\mathrm{p}$ \\
\hline $\begin{array}{c}\text { AST } \\
\text { (UI/L) }\end{array}$ & $\begin{array}{c}341,7 \pm \\
73,9^{\mathrm{a}}\end{array}$ & $\begin{array}{l}403,1 \pm \\
78,42^{\text {ab }}\end{array}$ & $\begin{array}{c}410,5 \pm \\
70,5^{\mathrm{bc}}\end{array}$ & $\begin{array}{c}426,5^{ \pm} \\
66,7^{c}\end{array}$ & 0,0049 \\
\hline $\begin{array}{l}\mathrm{LDH} \\
\text { (UI/L) }\end{array}$ & $\begin{array}{c}423,1 \pm \\
101,8^{a}\end{array}$ & $\begin{array}{l}534,4 \pm \\
131,8^{\text {ab }}\end{array}$ & $\begin{array}{c}628,5 \pm \\
100,6^{b}\end{array}$ & $\begin{array}{c}823,4 \pm \\
273,2^{c}\end{array}$ & $<0,0001$ \\
\hline
\end{tabular}

*Letras minúsculas diferentes na mesma linha denotam diferença estatística significativa entre as medias $(\mathrm{p}<0,05)$ obtido pelo teste de Tukey. T0 (obtida antes da cavalgada), T1 (obtida após 54 km), T2 (obtida após 80 km) e T3 (obtida após $100 \mathrm{~km}$ ).
Quadro 2. Valores das medianas, valores mínimos e máximos da atividade sérica de CK (UI/L) nos muares submetidos a cavalgada de $100 \mathrm{~km}$, nos momentos T0, T1, T2 e T3

\begin{tabular}{lccccc}
\hline & T0 $(\mathrm{n}=20)$ & $\mathrm{T} 1(\mathrm{n}=12)$ & $\mathrm{T} 2(\mathrm{n}=17)$ & $\mathrm{T} 3(\mathrm{n}=14)$ & $\mathrm{p}$ \\
\hline $\begin{array}{l}\text { Mediana } \\
\text { Valor }\end{array}$ & $231,3 \mathrm{a}^{*}$ & $310,6 \mathrm{a}$ & $253,2 \mathrm{a}$ & $476,0 \mathrm{a}$ & 0,1462 \\
mínimo & 141,8 & 145,2 & 135,0 & 162,0 & \\
Valor & 462,5 & 1259,0 & 2430,0 & 3265,0 & \\
\end{tabular}

máximo

* Letras minúsculas diferentes na mesma linha denotam diferença estatística significativa entre as medias $(\mathrm{p}<0,05)$ obtido pelo teste Kruskal-Wallis. T0 (obtida antes da cavalgada), T1 (obtida após $54 \mathrm{~km}$ ), T2 (obtida após $80 \mathrm{~km}$ ) e T3 (obtida após $100 \mathrm{~km}$ ).

\section{DISCUSSÃo}

Foi possível verificar uma oscilação no número de muares nos diferentes momentos de avaliação e isso ocorreu por motivos diversos, tais como remoção do animal da prova por opção do proprietário, lesões ou até mesmo dispersão após a chegada impossibilitando o acesso aos mesmos, refletindo uma das dificuldades encontradas em pesquisas a campo. Capelleto et al. (2009) relatam que as avaliações de desempenho de equinos podem ser realizadas em laboratórios equipados com esteira de alta velocidade ou a campo. Segundo esses mesmos autores, os protocolos de avaliação a campo incluem avaliações clínicas e coletas de amostras de sangue obtidas em intervalos determinados previamente, nos picos de exercícios submáximos ou no pico de um único exercício máximo. Nesses momentos também são feitos registros de informações relevantes, tais como temperatura local, umidade do ar e condições de pista.

Apesar de alguns autores como Tateo et al. (2008) ressaltarem que experimentos conduzidos a campo são difíceis de padronização por serem influenciados por diversos fatores externos, tais avaliações são importantes por imporem as reais condições encontradas a campo, além de auxiliarem na determinação de valores regionais de referência. Em sua pesquisa, Balarin et al. (2005) descreveram diferenças significativas para as diversas enzimas séricas em equinos da raça Puro Sangue Inglês de acordo com o local onde os experimentos foram realizados.

Os muares usados foram exercitados em dois dias, com média de velocidade imposta de $3,5 \mathrm{~km} / \mathrm{h}$ em pista de areia batida seca, com diversos trechos de subidas e declives. Segundo Tateo et al. (2008), é difícil de estabelecer a intensidade do exercício físico em avaliações a campo. Entretanto, Aguera et al. (2005) ressaltaram que as determinações da frequência cardíaca e do lactato plasmático podem ser usados como marcadores da intensidade do exercício. Na presente pesquisa, os valores registrados para frequência cardíaca e lactato plasmático foram, respectivamente de $45 \mathrm{bpm}$ e $1,09 \pm 0,43 \mathrm{mmol} / \mathrm{L}$ em T0, $72 \mathrm{bpm} \mathrm{e}$ $2,41 \pm 1,00 \mathrm{mmol} / \mathrm{L}$ em T1, 75bpm e $1,55 \pm 0,63 \mathrm{mmol} / \mathrm{L} \mathrm{em}$ T2 e $76 \mathrm{bpm}$ e $1,61 \pm 0,33 \mathrm{mmol} / \mathrm{L}$ em T3. 0 aumento da frequência cardíaca foi compatível com ao aumento do esforço físico, resultando em aumento da força de contração, volume ejetado e débito cardíaco. Já os valores registrados para lactato plasmático encaixam-se dentro da descrição de Falaschini \& Trombetta (2001). Segundo esses autores, exer- 
cícios de intensidade moderada (submáxima) e longa duração caracterizam-se por aumentos plasmáticos entre 2,5 e $4 \mathrm{mmol} / \mathrm{L}$, com predominância do metabolismo aeróbico.

$\mathrm{Na}$ avaliação do hemograma, os valores médios encontrados foram de $8,90 \times 10^{6} / \mu \mathrm{L}$ para número de eritrócitos, $12,9 \mathrm{~g} / \mathrm{dL}$ para concentração de hemoglobina e $38 \%$ para volume globular. Tais valores encontram-se dentro da normalidade segundo Robinson (2003), avaliando equinos da raça PSI, e superiores ao relato de Simenew et al. (2011), trabalhando com muares.

A avaliação das atividades séricas de AST, LDH e CK frente ao exercício caracterizou-se como um desafio a parte devido a grande diversidade na literatura consultada referente aos valores de repouso e valores registrados após a realização de uma atividade física. Em se tratando de muares, acrescenta-se a escassez de dados, com alguns autores como Etana et al. (2011) até considerando inválida as comparações dos valores registrados em muares com outras espécies como equinos e asininos.

É importante ressaltar, conforme também descreve Balarin et al. (2005) e Caiado et al. (2011), que os resultados laboratoriais devem ser sempre associados a um exame clínico minucioso. Isso foi realizado na presente pesquisa e mesmo os muares que apresentaram valores considerados elevados continuaram na prova por estarem clinicamente bem.

Em relação ao AST, foi possível observar que aumento significativo em suas concentrações séricas, com variação destacada entre os momentos T0 (antes) e T2-T3 (após percurso de $80 \mathrm{~km}$ ), semelhante ao descrito também por Valberg (1996), Câmara-Silva et al. (2007) e Tateo et al. (2008). Segundo esses autores, o aumento nas concentrações séricas da referida enzima ocorre em consequência do aumento da permeabilidade do sarcolema gerada pela atividade física. Seu pico de liberação acontece após 24 horas da execução da atividade física, podendo manter-se elevada por 5 dias ou até algumas semanas (Thomassian et al. 2007). Sendo assim, os resultados registrados em T2 e T3, segundo dia de atividade física, seriam reflexo do exercício imposto no primeiro dia. Todos os valores registrados na presente pesquisa encontram-se dentro dos limites fisiológicos citados por Pritchard et al. (2009), porém superiores aos descritos por Robinson (2003), Balarin et al. (2005), Franciscato et al. (2006) e Valberg (2008), lembrando que todos os autores supracitados trabalharam com equinos. Os valores da presente pesquisa foram ligeiramente superiores ao intervalo (142-404UI/L) descrito para muares por Simenew et al. (2011).

Opostamente, Ribeiro et al. (2004), que acompanharam prova de cavalgada no Pantanal, não observaram aumento significativo de AST nos muares, com valores descritos inferiores aos da presente pesquisa. Para os referidos autores, isso significou uma maior adaptação dessa espécie à prova e à região.

Em relação ao $\mathrm{LDH}$, também foi registrada diferença significativa entre os momentos T0, T2 e T3, com valores superiores a Balarin et al. (2005) e Câmara-Silva et al. (2007), que trabalharam com equinos, e a Ribeiro et al. (2004), que trabalharam com muares. Assim como AST, estas variações estariam relacionadas ao esforço físico, acarretando uma instabilidade tecidual e gerando o aumento de sua atividade plasmática, conforme citam Hodgson \& Rose (1994) e Teixeira-Neto (2006). Segundo Ribeiro et al. (2004), essa enzima sofre uma maior variação de valores por ser a menos específica das três estudadas.

Opostamente ao que foi registrado para AST e LDH, a avaliação das concentrações de CK nos diferentes momentos de avaliação não demonstrou diferença significativa. Isso difere dos achados de Valberg (1996), Balarin et al. (2005), Kowal et al. (2006) e Caiado et al. (2011), que registraram aumento significativo de CK sérica e justificaram essa elevação no pós-exercício pelo aumento da permeabilidade do sarcolema, com influência também do tipo de exercício e treinamento, semelhante ao AST e LDH (Câmara-Silva et al. 2007). Segundo Thomassian et al. (2007), aumentos de menor magnitude ou a não interferência nos valores de $\mathrm{CK}$, seriam resultados esperados após atividade física em equinos bem condicionados (Franciscato et al. 2006, Câmara-Silva et al. 2007). Tal descrição também foi feita por Rlibeiro et al. (2004) em muares, sugerindo que os animais da presente pesquisa encontravam-se aptos ao tipo de exercício físico imposto. Isso é reforçado pelo fato de que a CK é uma enzima de mais rápida liberação na circulação. Segundo Thomassian et al. (2007), o pico de liberação de CK acontece 4-6 horas após o exercício ou lesão com retorno aos níveis normais com 24-36 horas. Sendo as$\mathrm{sim}$, as pequenas alterações celulares, resultado do esforço físico imposto, não teriam sido suficientes para promover a liberação dessa enzima no plasma.

Os valores registrados para CK se encaixam dentro dos limites fisiológicos citados por Pritchard et al. (2009) e superiores ao descrito por Ribeiro et al. (2004), Balarin et al. (2005), Franciscato et al. (2006) e Valberg (2008).

\section{CONCLUSÕES}

Os resultados da presente pesquisa nos permitiram concluir que o exercício físico imposto levou ao aumento significativo de AST e LDH, porém não houve influência sobre os valores registrados para CK.

Foi também possível observar que os valores basais registrados para todas as enzimas estudadas nos muares usados foram superiores aos registrados em equinos; tais achados podem contribuir com aqueles escassos já descritos na literatura em relação aos valores de referência para a espécie, quando criados e trabalhados em condições tropicais.

Agradecimentos.- À FAPES (Fundação de Apoio a pesquisa do Estado do Espírito Santo), pela concessão da bolsa de mestrado.

\section{REFERÊNCIAS}

Aguera E.I., Rubio D., Vivo R., Santisteban R., Aguera S., Muñoz A. \& Castejon F.M. 1985. Heart rate and plasma lactate response to training in Andalusian horses. J. Eq. Vet. Sci. 15:532-536.

Balarin M.R.S., Lopes R.S., Kohayagawa A., Laposy C.B. \& Fonteque J.R. 2005. Avaliação da glicemia e da atividade sérica de aspartato aminotransferase, creatinoquinase, gama- glutamiltransferase e lactato desidrogenase em equinos puro sangue inglês (PSI) submetidos a exercícios de diferentes intensidades. Semina, Ciênc. Agrárias 26:211-218. 
Bergmeyer H.U. 1985. Methods of Enzymatic Analysis. 12 volumes. Academic Press, New York.

Caiado J.C.C., Pissinate G.L., Suza V.R.C., Fonseca L.A. \& Coelho C.S. 2011. Lactacidemia e concentrações séricas de aspartato aminotransferase e creatinoquinase em equinos da raça Quarto de Milha usados em provas de laço em dupla. Pesq. Vet. Bras. 31:452-458.

Câmara-Silva I.A., Dias R.V.C. \& Soto-Blanco B. 2007. Determinação das atividades séricas de creatina quinase, lactato desidrogenase e aspartato aminotransferase em equinos de diferentes categorias de atividade. Arq. Bras. Med. Vet. Zootec. 59:250-252.

Capelleto E.C., Angeli A.L. \& Graff H. 2009. Respostas fisiológicas em Quarto de Milha após aprova de tambor. Rev Acadêmica, Ciênc. Agr. Amb. 7:299-304.

De Oliveira J. 2004. Adequação da hemodiálise em equinos hígidos: Avaliação clínica e laboratorial. Tese de Doutorado, Universidade Federal de Minas Gerais, Belo Horizonte, MG. 289p.

Dugat S.L., Taylor T.S., Matthews N.S. \& Gold J.R. 2010. Values for Triglycerides, Insulin, Cortisol and ACTH in a Herd of Normal Donkeys. J. Eq. Vet. Sci. 30:141-144.

Etana K.M., Jenbere T.S., Bojia E. \& Negussie H. 2011. Determination of reference hematological and serum-biochemical values for working donkeys of Ethiopia. Vet. Res. 4:90-94.

Falaschini A. \& Trombetta M.F. 2001. Modifications induced by training and diet in some exercise-related blood parameters in young trotters. J. Eq. Vet. Sci. 21:601-604.

Franciscato C., Lopes S.T.A., Veiga A.P.M., Martins D.B., Emanuelli M.P. \& Oliveira L.S.S. 2006. Atividade sérica das enzimas AST, CK e GGT em cavalos Crioulos. Pesq. Agropec. Bras. 41:1561-1565.

Freestone J.F., Wolfsheimer K.J., Kamerling S.G., Church G., Hamra J. \& Baqwell C. 1991. Exercise induced hormonal and metabolic changes in Thoroughbred horses: effects of conditioning and acepromazine. Eq. Vet. J. 23:219-223.

Gomide L.M.W., Martins C.B., Orozco C.A.G., Sampaio R.C.L., Belli T., Baldissera V. \& Lacerda Neto J.C. 2006. Concentrações sanguíneas de lactato em equinos durante a prova de fundo do concurso completo de equitação. Ciência Rural 36:509-513.

Harris P.A., Marlin D.J. \& Gray J. 1998. Plasma aspartate aminotransferase and creatine kinase activities in thoroughbred racehorses in relation to age, sex, exercice and training. Vet. Journal 155:295-304.

Hodgson D.R. \& Rose R.J. 1994. Hematology and biochemistry, p.63-78. In: Hodgson D.R. \& Rose R.J. (Eds), The Athletic Horse: Principle and Practice of Equine Sports Medicine. W.B. Saunders, Philadelphia. 497p.

Kowal R.J., Almosny N.R.P., Cascardo B., Summa R.P. \& Cury L.J. 2006. Avaliação dos valores de lactato e da atividade sérica da enzima creatina quinase (2.7.3.2) em cavalos (Equus caballus) da raça Puro-Sangue-Inglês (PSI) submetidos a teste de esforço em esteira ergométrica. Revta Bras. Ciênc. Vet. 13:13-19.

Martins C.B., Orozco C.A.G., D`Angelis F.H.F., Freitas E.V.V., Christovão F.G., Queiroz Neto A. \& Lacerda Neto J.C. 2005. Determinação de variáveis bioquímicas em equinos antes e após a participação em provas de enduro. Revta Bras. Ciênc. Vet. 12:62-65.

Padalino B., Rubino G., Centoducati P. \& Petazzi F. 2007. Training versus overtraining: evaluation of two protocols. J. Eq. Vet. Sci. 27:28-31.

Pritchard J.C., Burn C.C., Barr A.R.S. \& Whay H.R. 2009. Haematological and serum biochemical reference values for apparently healthy working horses in Pakistan. Res. Vet. Sci. 87:389-395.

Ralston S.L. 1988. Equine Clinical Nutrition: specific problems and solutions. Comp. Cont. Educ. 10:356-363.

Ribeiro C.R., Martins E.A.N., Ribas J.A.S. \& Germinaro A. 2004. Avaliação de constituintes séricos em equinos e muares submetidos à prova de resistência de 76km, no Pantanal do Mato Grosso, Brasil. Ciência Rural 34:1081-1086.

Ribeiro A.L., Severino R.S., Guerra R.R., Favaron P.O., Tommasi Jr. H.L.P., Ricci R.E.G., Franciolli A.L.R., Facciotti P.R. \& Bombonato P.P. 2009. Biometria de pontes de miocárdio em muares (Equus caballus $\mathrm{x}$ Equus asinus - Linnaeus 1758). Revta Biotemas 22:177-184.

Robinson E.N. 2003. Current Therapy in Equine Medicine. $5^{\text {th }}$ ed. W.B. Saunders, Philadelphia. 960p.

Rose J.R., Arnold K.S. \& Church S. 1980. Plasma and sweat electrolyte concentrations in the horse during long distance exercise. Eq. Vet. J. 12:1922.

Santos V.P. 2006. Variações hemato-bioquímicas em equinos de salto submetidos a diferentes tipos de protocolos de exercício. Dissertação de Mestrado, Universidade Federal do Rio Grande do Sul, Porto Alegre, RS. $94 \mathrm{p}$.

Schmid M. \& Fostner L.A. 1986. Laboratory Testing in Veterinary Medicine Diagnosis in the Clinical Monitoring. Boehringer, Mannheim. 253p.

Simenew K., Gezahegne M., Getachew M., Wondyefraw M., Alemayehu L. \& Eyob I. 2011. Reference values of clinically important physiological, hematological and serum biochemical parameters of apparently healthy working equids of Ethiopia. Global Veterinária 7:1-6.

Tateo A., Valle E., Padalino B., Centoducati D.A. \& Bergero D. 2008. Change in some physiologic variables induced by Italian traditional conditioning in Standardbred yearling. J. Eq. Vet. Sci. 28:743-750.

Teixeira-Neto A.R. 2006. Variáveis fisiológicas e estresse oxidativo de equinos durante campeonato de enduro. Tese de Doutorado, Universidade Estadual Paulista, Jaboticabal, SP. 84p.

Thomassian A., Carvalho F., Watanabe M.J., Silveira V.F., Alves A.L., Hussni C.A. \& Nicoletti J.L.M. 2007. Atividades séricas da aspartato aminotransferase, creatina quinase e lactato desidrogenase de equinos submetidos ao teste padrão de exercício progressivo em esteira. Braz. J. Vet. Res. Anim. Sci. 44:183-190.

Valberg S.J. 1996. Muscular causes of exercise intolerance in horses. Vet. Clin. North Am., Equine. Pract. 12:495-515.

Valberg S.J. 2008. Skeletal muscle function, p.459-484. In: Kaneko J.J., Harvey J.W. \& Bruss M.L. (Eds), Clinical Biochemistry of Domestic Animals. $6^{\text {th }}$ ed. Academic Press, London. 916p. 